\title{
Darcy Fontoura de Almeida (1930-2014)
}

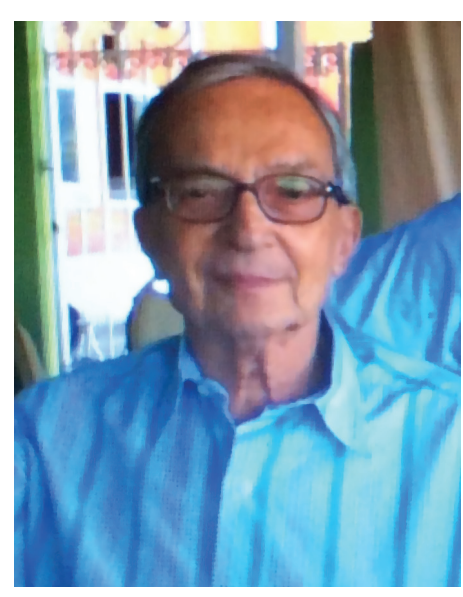

One of the first scientists to work with bacterial genetics in Brazil and a prominent member of the Brazilian Society of Genetics (SBG), Darcy Fontoura de Almeida died last March $6^{\text {th }}$ in Rio de Janeiro due to a respiratory infection. DFA, as he was frequently referred to, graduated from the National Medicine Faculty at the University of Brazil in 1954 and carried out post-graduate studies at the Hammersmith Hospital, London, in 1956. His scientific life started during a training period as an undergraduate student at the Biophysics Institute of the Federal University of Rio de Janeiro (UFRJ) under the supervision of Dr. Carlos Chagas Filho. During that period, he worked with the physiology of bioelectrogenesis with the electric eel (Electrophorus electricus). His interest in bacterial genetics grew after contacts with different scientists outside the country, including Dr. Ernst Chain (who shared a Nobel Prize in Medicine with Alexander Fleming and Howard Florey, in 1945) and Dr. James T. Walker, at the University of Texas, who helped him to establish at the UFRJ studies dealing with the map of genes in the Escherichia coli chromosomal DNA. He applied these techniques to study genes that play a role in the genetic control of cell division in E. coli, which resulted in the identification of the $f t s H$ gene, later identified as the first member of a protease family (AAA proteases) involved with development and cell differentiation in different organisms, including humans. The scientific interests of DFA expanded to other research areas including plasmids encoding antibiotic resistance genes among Salmonella strains, genetics of the protozoan Trypanosoma cruzi, and genes involved in the pathogenesis of $E$. coli strains, particularly enterotoxigenic E. coli (ETEC) strains, and their use in the development of vaccines against travellers diarrhea. In the 90's, DFA became more interested in the study of bacterial genomes, the role of non-coding DNA sequences and the use of bioinformatics tools to analyze the genomes of different bacterial species. From his pioneering studies in this field resulted a fruitful cooperation with the National Laboratory for Sci- entific Computing (LNCC). Based on his inspiration and efforts in that field, the LNCC created the "Darcy Fontoura de Almeida Unit of Computational Genomics" in his honor, which is dedicated to sequencing and development of bioinformatics tools for genome research. DFA was also known for his dedication and excitement with the advancement of science in Brazil. He was a member and former president of the Brazilian Genetics Society (SBG), the Brazilian Society for the Advancement of Science (SBPC), Brazilian Academy of Sciences (ABC), member of the evaluation boards of different Brazilian financial agencies, such as FINEP, CAPES, and CNPq. DFA was also the director of the Carlos Chagas Filho Biophysics Institute (1985-89), member of the International Federation of Institutes for Advanced Study, emeritus professor at the UFRJ and co-founder of the "Ciência Hoje" and "Ciência Hoje das Crianças" magazines and the Science Journal of SBPC. In 2007, the SBG distinguished DFA for his contributions to the Brazilian sciences giving him a prize for his contributions in the field of microbial genetics. DFA also received the National Medal for Scientific Merit by the Federal Government. Since 2001, DFA worked as a visiting scientist at the Oswaldo Cruz Foundation, where he dedicated part of his time to contemporary history of science in Brazil, particularly, describing the contributions of Dr. Carlos Chagas Filho to the advancement of science in the country. DFA published approximately 80 scientific articles and advised approximately 30 master and doctorate theses. Some of his previous students are presently working in different universities and scientific institutes in the country. Most relevantly, DFA left to all who knew him in life and all who presently work with microbial genetics and genome analyses a sense of recognition for his contributions to the advancement of science in Brazil. Indeed, an extraordinary human being.

Ana Tereza Ribeiro de Vasconcelos Laboratório Nacional de Computação Científica Rio de Janeiro, RJ

Sergio Olavo Pinto da Costa Instituto de Ciências Biomédicas Universidade de São Paulo, São Paulo, SP

Samuel Goldenberg Instituto Carlos Chagas Fundação Oswaldo Cruz, Curitiva, PR

Luís Carlos de Souza Ferreira Instituto de Ciências Biomédicas Universidade de São Paulo, São Paulo, SP 